\title{
Introduction of the Critical Care Corner
}

elSSN: 2383-4625

\author{
Adam J Singer ${ }^{1}$, Scott Weingart ${ }^{2}$ \\ ${ }^{1}$ Editor-in-Chief \\ ${ }^{2}$ Critical Care Corner Section Editor
}

In this, our forth, issue of Clinical and Experimental Emergency Medicine, we are pleased to introduce a new section titled, 'Critical Care Corner (CCC).' This section will be edited by Dr. Scott Weingart, a board certified emergency and critical care physician, widely known for his most popular blog EMCrit. This section will present brief diagnostic or therapeutic 'pearls' that should be very useful to practicing emergency and critical care physicians. This section will be limited to 500-1,000 words, 10 references and a single table or figure.

While some of the contributions to CCC will be solicited by the section editor, those interested in submitting an unsolicited manuscript are encouraged to do so. In the current issue of Clinical and Experimental Emergency Medicine, the CCC addresses the use of intravenous boluses of vasopressors for hypotensive patients in the emergency department and critical care unit. This practice, common in the operating room, has only recently been introduced to the emergency department. However, this simple intervention may prevent further deterioration and even cardiac arrest in some crashing presents. We hope that our readers will find this section helpful in their day-to-day practice.

\section{CONFLICT OF INTEREST}

No potential conflict of interest relevant to this article was reported. 